\title{
Palliative Care for Cancer Patients During the COVID-19 Pandemic, With Special Focus on Lung Cancer
}

\author{
Janna J. A. O. Schoenmaekers ${ }^{1,2 * t}$, Lizza E. L. Hendriks ${ }^{1 \dagger}$, Marieke H. J. van den \\ Beuken-van Everdingen ${ }^{2,3+}$
}

${ }^{1}$ Department of Pulmonary Diseases, GROW-School for Oncology and Developmental Biology, Maastricht University Medical Centre+, Maastricht, Netherlands, ${ }^{2}$ Centre of Expertise for Palliative Care, Maastricht University Medical Centre+,

Maastricht, Netherlands, ${ }^{3}$ Department of Optimising Patient Care, School for Care Public Health Research Institute (CAPHRI), Maastricht University, Maastricht, Netherlands

Keywords: coronavirus, pandemic, lung cancer, palliative care, telemedicine

\section{INTRODUCTION}

\section{OPEN ACCESS}

Edited by:

Sara Pilotto,

University of Verona, Italy

Reviewed by:

Karen L. Reckamp,

Cedars-Sinai Medical Center,

United States

Raffaele Giusti,

Sant' Andrea Hospital, Italy

*Correspondence:

Janna J. A. O. Schoenmaekers

j.schoenmaekers@mumc.n

tThese authors have contributed equally to this work

Specialty section:

This article was submitted to

Thoracic Oncology,

a section of the journal

Frontiers in Oncology

Received: 29 April 2020

Accepted: 03 July 2020

Published: 21 July 2020

Citation:

Schoenmaekers JJAO, Hendriks LEL and van den Beuken-van Everdingen MHJ (2020) Palliative Care for Cancer

Patients During the COVID-19

Pandemic, With Special Focus on

Lung Cancer. Front. Oncol. 10:1405.

doi: 10.3389/fonc. 2020.01405
The COVID-19 pandemic causes a massive shift in the distribution of health care. Due to the high number of patients needing hospitalization and even intensive care unit (ICU) treatment, health care professionals (HCP) are often redeployed from their original specialization to COVID-19 treatment. This potentially compromises the care for others, such as oncology patients. Furthermore, cancer patients, the elderly, and those with comorbidities are at high risk of developing COVID-19 related morbidity and mortality $(1,2)$. This is especially true for lung cancer patients, with reported mortality rates of $25-55 \%$ (3-6), compared with up to $10 \%$ in other COVID-19 patients (5), which can be explained by the fact that several risk factors for severe COVID-19 can be found in the group of patients with lung cancer: cancer itself, its potentially immunosuppressive treatment, a high median age ( $>70$ years), often a smoking history, and a high percentage of comorbidities (7-10). Furthermore, outpatient clinic, daycare as well as hospital visits might increase the risk of contracting COVID-19. To minimize COVID-19 related risks, the risk/benefit ratio for all (lung) cancer treatments, including systemic anticancer treatment must be reconsidered (11). During infectious disease outbreaks, actions taken by public health authorities to limit the spread of disease can exacerbate psychological, social, and spiritual suffering, as was seen during the Ebola epidemic in 2014-2015 and the SARS epidemic in 2002 (12, 13). However, already in 2018, the World Health Organization (WHO) stated: "In epidemics of life-threatening infections, as in other Humanitarian emergencies and crises, the suffering of victims and efforts to relieve it, often are neglected in haste to save lives. Yet, palliative care in these situations is just as critical" (14).

Till now, for (lung) cancer, the focus has been on how to optimize treatment pathways during the pandemic. The continuation of palliative care is essential as well since early integration of palliative care leads to significant improvements in quality of life (QoL), mood, and possibly also longer overall survival (OS) (15). However, during the COVID-19 pandemic, palliative care isjeopardized in all four pillars (physical, psychological, social, and spiritual). Patients are anxious to visit the hospital and HCP are encouraged to avoid face-to-face contacts as much as possible (16).

As the first wave of the COVID-19 pandemic seems to be behind us in Europe, and the health care systems return to normal, we can look back and reflect on things we have learned until now. We can also use this knowledge in countries where the pandemic is still ongoing. In this opinion article, we will focus on the impact that COVID-19 had on palliative care for (lung) cancer patients, and we will provide practical advice on how to maintain and improve palliative care in times of a resurgence of the virus. A summary is also provided in Table $\mathbf{1 .}$ 
TABLE 1 | Summary problems and possible solutions of palliative care for non-COVID lung cancer patients during the COVID-19 pandemic.

\begin{tabular}{|c|c|c|}
\hline $\begin{array}{l}\text { Domain of } \\
\text { palliative } \\
\text { care }\end{array}$ & $\begin{array}{l}\text { Problems during } \\
\text { COVID-19 } \\
\text { pandemic }\end{array}$ & Possible solution \\
\hline Psychological & $\begin{array}{l}\text { - Anxiety for } \\
\text { COVID-19 but } \\
\text { also for cancer } \\
\text { treatment } \\
\text { changes } \\
\text { - Depression due } \\
\text { to social } \\
\text { isolation }\end{array}$ & $\begin{array}{l}\text { - Self-care and distress management tools. } \\
\text { Links with examples of self-care tools for } \\
\text { patients or clinicians are found below. } \\
\text { - https://www.nccn.org/covid-19/pdf/ } \\
\text { NCCN_Patient_Self_Care_COVID-19. } \\
\text { pdf (17) } \\
\text { - https://helixcentre.com/project-end-of- } \\
\text { life-toolkit (18) } \\
\text { - https://www.nccn.org/covid-19/pdf/ } \\
\text { Distress-Management-Clinician- } \\
\text { COVID-19.pdf (19) } \\
\text { - Telemedicine }\end{array}$ \\
\hline Social & $\begin{array}{l}\text { - Social distancing } \\
\text { and therefore } \\
\text { lack of } \\
\text { social support }\end{array}$ & - Technical applications for video calling \\
\hline Physical & $\begin{array}{l}\text { - Shortage of } \\
\text { drugs } \\
\text { - Shortage of } \\
\text { materials such } \\
\text { as pump drivers } \\
\text { - Shortage of } \\
\text { caregivers } \\
\text { - Minimized } \\
\text { face-to-face } \\
\text { contact between } \\
\text { treating } \\
\text { physician } \\
\text { and patient }\end{array}$ & $\begin{array}{l}\text { - Adapting guidelines with alternative drugs } \\
\text { and pump systems. If a shortage is } \\
\text { impending it is recommended to look at } \\
\text { the local (changed) guidelines, because the } \\
\text { local availability of products can be different } \\
\text { in every region. Links to currently adapted } \\
\text { guidelines are found below. } \\
\text { - https://www.palliativecareguidelines. } \\
\text { scot.nhs.uk/guidelines/symptom- } \\
\text { control/alternatives-to-regular- } \\
\text { medication-normally-given-via-a- } \\
\text { syringe-pump-when-this-is-not- } \\
\text { available.aspx (20) } \\
\text { - https://www.esmo.org/content/ } \\
\text { download/286441/5690599/1 (21) } \\
\text { - https://www.esmo.org/content/ } \\
\text { download/286432/5690545/1 (22) } \\
\text { - Telemedicine } \\
\text { - Adapting palliative care for specific } \\
\text { complaints } \\
\text { - Painful bone metastases: avoid RTx } \\
\text { when pain controlled by level 1-3 oral } \\
\text { analgesics. If RTx necessary, mono- } \\
\text { fractionated (8 Gy in } 1 \text { fr) (23) } \\
\text { - Thoracic RTx: palliative RTx for } \\
\text { indwelling catheter when in need of } \\
\text { frequent pleural fluid drainage (25) }\end{array}$ \\
\hline Spiritual & $\begin{array}{l}\text { - Loss of sense of } \\
\text { meaning of life } \\
\text { - Loss of faith }\end{array}$ & $\begin{array}{l}\text { - Seek partnership with local } \\
\text { spiritual counselors }\end{array}$ \\
\hline
\end{tabular}

COVID-19, corona virus disease 2019; RTx, radiotherapy; Gy, Gray; fr, fraction.

\section{PALLIATIVE CARE DURING COVID-19}

\section{Palliative Care Services and Redeployment of Personnel}

Palliative care teams and hospice services have an essential role in response to COVID-19. A systematic review identified the following important issues: a rapid and flexible response, availability of protocols for symptom management, palliative care specialists involved in triage, the possibility of shifting resources from inpatient to community settings (the demand there may be higher), the possibility of redeploying volunteers to provide psychosocial, and bereavement care and the use of technology to communicate with patients and caregivers (26). This is described in more detail below.

The workload for palliative care teams increased during the pandemic. Because most teams are small in number and the different providers have complementary roles, it is vital to keep the existing palliative care providers free from COVID-19 (27). By coaching primary health care teams with guidelines and order sets for the management of COVID-19 symptoms, the optimal use of palliative care consultation for non-COVID-19 patients could be ensured.

Caregivers and volunteers in hospice care were at higher risk of and had a fear of infection; as a result, personnel and volunteers fell short. Therefore, some hospices even closed their doors $(28,29)$. The shortage of home-care nurses due to an increase in patients and illness of the nurses themselves was a threat to the delivery of adequate palliative care. There was even set up an agreement that in case of lack of community nurses to administer drugs, a family member could be taught, under strict conditions, to deliver intermittent morphine subcutaneously, although this was not desirable. This could save HCP as the syringes can be prepared for $24 \mathrm{~h}$ of drug administration, once daily, by trained nurses.

\section{Palliative Care Services and Scarcity of Resources}

Besides the understaffing, other resources ran short (such as face masks and other protective equipment). There was a (risk of) shortages in certain commonly used drugs such as morphine, midazolam, lorazepam, and propofol. These are all medications used to relieve symptoms in the palliative and terminal stages of patients with cancer. Morphine has been proven to be an effective treatment for refractory breathlessness $(30,31)$. The risk of a shortage of morphine existed, but other drugs are not effective [oxycodone (32)], or only anecdotal proof of its effectiveness on dyspnea exists [fentanyl $(33,34)]$. To guide physicians in the use of other opioids in the treatment of dyspnea, local guidelines rapidly changed, or expanded with recommendations in times of shortages. For example, in the Netherlands, the guideline "symptomatic treatment of dyspnea" temporarily expanded with recommendations concerning the use of Rapid Onset Opioids (ROO's). Importantly, these recommendations have also been adopted by the European Society for Medical Oncology (ESMO) $(21,22)$.

Midazolam and propofol, delivered as a continuous intravenous or subcutaneous infusion, are used in protocols for palliative sedation. The impending shortages of medication and pumps asked for "what if" scenarios. As an example, in the Netherlands, a new guideline "palliative sedation in times of COVID-19" was written by a group of palliative care experts and endorsed by the relevant scientific associations, including ESMO $(21,22)$.

Other countries, such as the United Kingdom, have also rapidly set up guidelines on how to act when conventional drugs 
and pump systems are not available. Therefore, when a shortage in certain drugs is foreseen in a second COVID-19 wave, it is recommended to look at the local (changed) guidelines, because the local availability of products can be different in every region (20). The links to the currently available guidelines can be found in Table 1.

\section{Telemedicine}

Flexibility and resilience have been fundamental tools to overcome critical issues. The health care system adapted fast to the changing practice and telemedicine was quickly implemented. Previously, the use of telemedicine in palliative care showed improvements in symptom management, comfort with care, and patient and family satisfaction (35). It also facilitated cooperation between the community nurses and the specialized palliative care team nurse (36). Still, potential barriers were technology-related complications in the elderly and frail population (35) and private issues regarding the illness, with family members present (36). Moreover, patients, as well as physicians, did not always feel comfortable with non-face-toface physician care. Telemedicine also has hidden advantages: it allows HCP to see patients' home environments, information that is usually lacking. Before considering telemedicine the norm, it is important to remember that at least one randomized controlled trial (RCT) of weekly palliative care teleconsultations vs. inperson palliative care showed significantly more anxiety and higher distress in the telehealth group $(37,38)$. The corona crisis forced patients, their families, and HCP to implement telemedicine rapidly. This was also for the inpatients due to quarantine with increasingly isolated hospitalized patients (39). However, videoconferencing and online services stay second- best in palliative care. It cannot replace the sittingdown with a patient, nor the comforting touch, but it enabled HCP to pick-up non-verbal clues and emotions essential for good communication.

\section{CHANGES DUE TO COVID-19 PANDEMIC IN FOUR PILLARS OF PALLIATIVE CARE \\ Physical}

Palliative care for specific complaints has been adapted as well. The ESMO published guidance for cancer care during COVID-19, including a part on palliative care prioritization. The underlying principles included: (1) continuing to prioritize the relief of severe distress and the management of severe acute complications of cancer (such as cord compression, symptomatic brain metastases in patients with good performance status, pleural effusion, severe dyspnea, pain, etc.), (2) managing many symptom control issues by telephone when possible, and (3) arranging home care services whenever possible for patients with anticipated high palliative care needs (40). To minimize the risk for patients, time they spend at the hospital should be reduced. Recommendations for specific complaints and treatments such as radiotherapy are described in Table $\mathbf{1}$, and will not be described in detail in the text.

\section{Psychological and Social}

For (lung) cancer patients, the psychosocial impact of the COVID-19 pandemic was substantial. During the peak, social life was disrupted because of social distancing. Visits from friends and family were lacking, but also the visits of formal /informal caregivers were limited. Due to the fear of becoming infected, patients isolated themselves even more (41). However, social support has been shown to improve QoL in lung cancer patients (42), and lung cancer patients indicate that they indeed need family support during treatment (43). In colorectal cancer, good social integration was even associated with improved survival (44).

Besides anxiety and fear due to the diagnosis of cancer, in the COVID-19 pandemic, these complaints also arose from adjusted or postponed treatments. Therefore, uncertainty about the future increased. Also, the duration of the pandemic has been uncertain, and unfortunately, straightforward information regarding the lung cancer treatment plan was lacking. In patients treated with palliative intent, outside of the COVID-19 pandemic, fear of metastases and insecurity about the future is already increased compared with those treated with curative intent (43). The Dutch federation of cancer patient organizations (NFK) collected through a survey the experiences of patients with cancer. Twelve percent of the responders were lung cancer patients. Fifty-five percent of all patients were worried to contract a COVID19 infection, and $26 \%$ had (several) concerns regarding the consequences of COVID-19 on anti-cancer treatment or followup (45). Palliative care in this patient population is important, as it has been previously shown that this can reduce fear and anxiety (46). The National Comprehensive Cancer Network (NCCN) has developed a self-care and distress management tool for cancer patients, with information about how to obtain up-to-date information, manage distress and improve resilience, but this tool does not specifically focus on patients treated with palliative intent (17).

Self-isolation affects not only the lung cancer patient but also their informal caregivers, as social support and psychosocial interventions, although effective (47), decreased for this group, while the burden of caregiving remained. Furthermore, informal caregivers were increasingly confronted with patients dying at home, as hospices were less available, and professional HCP reduced their visits. To anticipate problems and questions, end-of-life toolkits were developed, for example, in the United Kingdom (18).

COVID-19 related mortality is higher in cancer patients compared with the general patients. An international registrybased cohort study showed a mortality rate of $33 \%$ among patients with thoracic cancer (6). As "normal" mourning and burial rituals were not possible due to the social distancing, the mourning of loved ones that stay behind will be influenced (48).

Visits to the outpatient clinic were reduced in most hospitals, and most of the consultations were by telephone. Not all hospitals had videoconferencing in place. Therefore, non-verbal communication was hampered. Without non-verbal communication, psychological stress from patients or relatives is less recognized (49), 
and empathy and respect toward the patient are less conveyed (50).

Importantly, non-verbal communication can help recall information given in the consultation by the patient (51), which would improve therapy adherence and probably also reduce insecurity, fear, and anxiety in patients, and their relatives.

Furthermore, due to shifting tasks and a higher number of working hours, combined with the risk of COVID-19 infection, HCP themselves are at risk of psychosocial problems or burnout (52). This also limited their ability to provide palliative care for patients (53). Organizations such as the NCCN have also published toolkits for HCP (19).

\section{Spiritual}

The importance of spirituality in coping with uncertainty, severe disease, and at the end of life is recognized. Spiritual well-being offers some protection against end-of-life despair in those for whom death is imminent (54). There is a positive and significant relationship between spiritual wellbeing, mental health, and QoL in cancer patients (55). Spiritual suffering during the COVID-19 pandemic can intensify the feeling of loss of sense of the meaning of life and even loss of faith. Therefore, it is important to seek partnership with

\section{REFERENCES}

1. Zhang L, Zhu F, Xie L, Wang C, Wang J, Chen R, et al. Clinical characteristics of COVID-19-infected cancer patients: a retrospective case study in three hospitals within Wuhan, China. Ann Oncol. (2020) 31:894901. doi: 10.1016/j.annonc.2020.03.296

2. Guan WJ, Ni ZY, Hu Y, Liang WH, Ou CQ, He JX, et al. Clinical characteristics of coronavirus disease 2019 in China. N Engl J Med. (2020) 382:170820. doi: $10.1056 /$ NEJMoa2002032

3. Mehta V, Goel S, Kabarriti R, Cole D, Goldfinger M, AcunaVillaorduna A, et al. Case fatality rate of cancer patients with COVID-19 in a New York Hospital system. Cancer Discov. (2020) 10:935-41. doi: 10.1158/2159-8290.CD-20-0516

4. Yang $\mathrm{K}$, Sheng $\mathrm{Y}$, Huang $\mathrm{C}$, Jin Y, Xiong N, Jiang K, et al. Clinical characteristics, outcomes, and risk factors for mortality in patients with cancer and COVID-19 in Hubei, China: a multicentre, retrospective, cohort study. Lancet Oncol. (2020) 21:904-13. doi: 10.1016/S1470-2045(20)30310-7

5. Rogado J, Pangua C, Serrano-Montero G, Obispo B, Marino AM, Perez-Perez M, et al. Covid-19 and lung cancer: a greater fatality rate? Lung Cancer. (2020) 146:19-22. doi: 10.1016/j.lungcan.2020.05.034

6. Garassino MC, Whisenant JG, Huang LC, Trama A, Torri V, Agustoni F, et al. COVID-19 in patients with thoracic malignancies (TERAVOLT): first results of an international, registry-based, cohort study. Lancet Oncol. (2020) 21:914-22. doi: 10.1016/S1470-2045(20)30314-4

7. Cai H. Sex difference and smoking predisposition in patients with COVID-19. Lancet Respir Med. (2020) 8:e20. doi: 10.1016/S2213-2600(20)30117-X

8. Onder G, Rezza G, Brusaferro S. Case-fatality rate and characteristics of patients dying in relation to COVID-19 in Italy. JAMA. (2020) doi: 10.1001/jama.2020.4683. [Epub ahead of print].

9. Wu Z, McGoogan JM. Characteristics of and important lessons from the coronavirus disease (2019). (COVID-19) outbreak in China: summary of a report of 72314 cases from the chinese center for disease control and prevention. JAMA. (2020). doi: 10.1001/jama.2020.2648. [Epub ahead of print].

10. Addeo A, Obeid M, Friedlaender A. COVID-19 and lung cancer: risks, mechanisms and treatment interactions. J Immunother Cancer. (2020) 8:e000892 doi: $10.1136 /$ jitc-2020-000892 local spiritual counselors willing to visit patients and family members on request face-to-face when possible or otherwise with telemedicine (14).

\section{CONCLUSION}

The COVID-19 pandemic changed the health care systems. As face-to-face contacts were severely reduced, and there was a risk of a shortage of specific resources used in palliative care medicine, palliative care for (lung) cancer patients was jeopardized.

By changing and evolving current guidelines rapidly and adopting new ways of communication with, for instance, telemedicine palliative care could be maintained as good as possible.

An important lesson to be learned from this crisis is that resilience and flexibility of the health care system and HCP are crucial.

\section{AUTHOR CONTRIBUTIONS}

All authors listed have made a substantial, direct and intellectual contribution to the work, and approved it for publication.
11. Liang W, Guan W, Chen R, Wang W, Li J, Xu K, et al. Cancer patients in SARS-CoV-2 infection: a nationwide analysis in China. Lancet Oncol. (2020) 21:335-7. doi: 10.1016/S1470-2045(20)30096-6

12. Hawryluck L, Gold WL, Robinson S, Pogorski S, Galea S, Styra R. SARS control and psychological effects of quarantine, Toronto, Canada. Emerg Infect Dis. (2004) 10:1206-12. doi: 10.3201/eid1007. 030703

13. Thomas SP. Ebola and mental health. Issues Ment Health Nurs. (2015) 36:2478. doi: 10.3109/01612840.2015.1023616

14. WHO. Integrating Palliative Care and Symptom Relief Into the Response to Humanitarian Emergencies and Crises: A WHO Guide. Geneva: WHO (2018). Contract No.: Licence: CC BY-NC-SA 3.0 IGO.

15. Temel JS, Greer JA, Muzikansky A, Gallagher ER, Admane S, Jackson VA, et al. Early palliative care for patients with metastatic non-small-cell lung cancer. $N$ Engl J Med. (2010) 363:733-42. doi: 10.1056/NEJMoa1000678

16. Cinar P, Kubal T, Freifeld A, Mishra A, Shulman L, Bachman J, et al. Safety at the time of the COVID-19 pandemic: how to keep our oncology patients and healthcare workers safe. J Natl Compr Canc Netw. (2020) 2020:16. doi: $10.6004 /$ jnccn. 2020.7572

17. NCCN. SELF-CARE \& DISTRESS MANAGEMENT DURING THE COVID19 PANDEMIC. (2020). Available online at: https://www.nccn.org/covid-19/ pdf/NCCN_Patient_Self_Care_COVID-19.pdf (accessed January 04, 2020).

18. Helixcentre. End-of-life Care Toolkits for Carers at Home. (2020). Available online at: https://helixcentre.com/project-end-of-life-toolkit (accessed April 29, 2020).

19. NCCN. Self-Care and Stress Management During the COVID-19 Crisis:Toolkit for Oncology Health Care Professionals. (2020). Available online at: https:// www.nccn.org/covid-19/pdf/Distress-Management-Clinician-COVID- 19. pdf (accessed April 29, 2020).

20. Scotland N. Alternatives to Regular Medication Normally Given via a Syringe Pump When This is not Available. (2020). Available online at: https:// www.palliativecareguidelines.scot.nhs.uk/guidelines/symptom-control/ alternatives- to-regular-medication-normally-given-via-a-syringe-pumpwhen-this-is-not-available.aspx (accessed June 18, 2020).

21. ESMO. Emergency Palliation Protocol for Non-Ventilated COVID-19 PatientsInpatient Version. (2020). Available online at: https://www.esmo.org/content/ download/286441/5690599/1 (accessed June 18, 2020). 
22. ESMO. Emergency Palliation Protocol for Non-Ventilated COVID-19 PatientsHomecare Version. (2020). Available online at: https://www.esmo.org/content/ download/286432/5690545/1 (accessed June 18, 2020).

23. Thureau S, Faivre JC, Assaker R, Biver E, Confavreux CB, Debiais $\mathrm{F}$, et al. Adapting palliative radiation therapy for bone metastases during the Covid-19 pandemic: GEMO position paper. J Bone Oncol. (2020). doi: 10.1016/j.jbo.2020.100291. [Epub ahead of print].

24. Guckenberger M, Belka C, Bezjak A, Bradley J, Daly ME, DeRuysscher D, et al. Practice recommendations for lung cancer radiotherapy during the COVID-19 pandemic: an ESTRO-ASTRO consensus statement. Radiother Oncol. (2020) 146:223-9. doi: 10.1016/j.radonc.2020.04.001

25. Boshuizen RC, Vd Noort V, Burgers JA, Herder GJM, Hashemi SMS, Hiltermann TJN, et al. A randomized controlled trial comparing indwelling pleural catheters with talc pleurodesis (NVALT-14). Lung Cancer. (2017) 108:9-14. doi: 10.1016/j.lungcan.2017.01.019

26. Etkind SN, Bone AE, Lovell N, Cripps RL, Harding R, Higginson IJ, et al. The role and response of palliative care and hospice services in epidemics and pandemics: a rapid review to inform practice during the COVID-19 pandemic. J Pain Symptom Manage. (2020) 60:e3140. doi: 10.1016/j.jpainsymman.2020.03.029

27. Rogers M, Meier DE, Heitner R, Aldridge M, Hill Spragens L, Kelley A, et al. The national palliative care registry: a decade of supporting growth and sustainability of palliative care programs. J Palliat Med. (2019) 22:102631. doi: $10.1089 / \mathrm{jpm} .2019 .0262$

28. Costantini M, Sleeman KE, Peruselli C, Higginson IJ. Response and role of palliative care during the COVID-19 pandemic: a national telephone survey of hospices in Italy. Palliat Med. (2020) 34:88995. doi: 10.1101/2020.03.18.20038448

29. Cheng HW, Li CW, Chan KY, Sham MK. The first confirmed case of human avian influenza $\mathrm{A}(\mathrm{H} 7 \mathrm{~N} 9)$ in Hong Kong and the suspension of volunteer services: impact on palliative care. J Pain Symptom Manage. (2014) 47:e57. doi: 10.1016/j.jpainsymman.2013.12.234

30. Barnes H, McDonald J, Smallwood N, Manser R. Opioids for the palliation of refractory breathlessness in adults with advanced disease and terminal illness. Cochrane Database Syst Rev. (2016) 3:CD011008. doi: 10.1002/14651858.CD011008.pub2

31. Ekstrom M, Bajwah S, Bland JM, Currow DC, Hussain J, Johnson MJ. One evidence base; three stories: do opioids relieve chronic breathlessness? Thorax. (2018) 73:88-90. doi: 10.1136/thoraxjnl-2016-209868

32. Ferreira DH, Louw S, McCloud P, Fazekas B, McDonald CF, Agar MR, et al. Controlled-release oxycodone vs. placebo in the treatment of chronic breathlessness-a multisite randomized placebo controlled trial. $J$ Pain Symptom Manage. (2020) 59:581-9. doi: 10.1016/j.jpainsymman.2019.10.017

33. Hui D, Kilgore K, Frisbee-Hume S, Park M, Liu D, Balachandran DD, et al. Effect of prophylactic fentanyl buccal tablet on episodic exertional dyspnea: a pilot double-blind randomized controlled trial. J Pain Symptom Manage. (2017) 54:798-805. doi: 10.1016/j.jpainsymman.2017.08.001

34. Benitez-Rosario MA, Rosa-Gonzalez I, Gonzalez-Davila E, Sanz E. Fentanyl treatment for end-of-life dyspnoea relief in advanced cancer patients. Support Care Cancer. (2019) 27:157-64. doi: 10.1007/s00520-018-4309-8

35. Worster B, Swartz K. Telemedicine and palliative care: an increasing role in supportive oncology. Curr Oncol Rep. (2017) 19:37. doi: 10.1007/s11912-017-0600-y

36. Funderskov KF, Boe Danbjorg D, Jess M, Munk L, Olsen Zwisler AD, Dieperink KB. Telemedicine in specialised palliative care: healthcare professionals' and their perspectives on video consultations-a qualitative study. J Clin Nurs. (2019) 28:3966-76. doi: 10.1111/jocn.15004

37. Mehta AK, Smith TJ. Palliative care for patients with cancer in the COVID-19 era. JAMA Oncol. (2020). doi: 10.1001/jamaoncol.2020.1938. [Epub ahead of print].

38. Hoek PD, Schers HJ, Bronkhorst EM, Vissers KCP, Hasselaar JGJ. The effect of weekly specialist palliative care teleconsultations in patients with advanced cancer -a randomized clinical trial. BMC Med. (2017) 15:119. doi: 10.1186/s12916-017-0866-9

39. Humphreys J, Schoenherr L, Elia G, Saks NT, Brown C, Barbour S, et al. Rapid implementation of inpatient telepalliative medicine consultations during COVID-19 pandemic. J Pain Symptom Manage. (2020) 60:e549. doi: 10.1016/j.jpainsymman.2020.04.001
40. Matti Aapro AA, Paolo Acierto, Thomas Berg, Iliaria Betella, Jean-Yves Blay et al. ESMO Guideline: Cancer Patient Management During the COVID19 Pandemic. (2020). Available online at: https://www.esmo.org/guidelines/ cancer-patient-management-during-the-covid-19-pandemic (accessed June $18,2020)$.

41. Cosic K, Popovic S, Sarlija M, Kesedzic I. Impact of human disasters and COVID-19 pandemic on mental health: potential of digital psychiatry. Psychiatr Danub. (2020) 32:25-31. doi: 10.24869/psyd.2020.25

42. Yoo H, Shin DW, Jeong A, Kim SY, Yang HK, Kim JS, et al. Perceived social support and its impact on depression and health-related quality of life: a comparison between cancer patients and general population. Jpn J Clin Oncol. (2017) 47:728-34. doi: 10.1093/jjco/hyx064

43. Looijmans M, van Manen AS, Traa MJ, Kloover JS, Kessels BLJ, de Vries J. Psychosocial consequences of diagnosis and treatment of lung cancer and evaluation of the need for a lung cancer specific instrument using focus group methodology. Support Care Cancer. (2018) 26:417785. doi: 10.1007/s00520-018-4291-1

44. Sarma EA, Kawachi I, Poole EM, Tworoger SS, Giovannucci EL, Fuchs CS, et al. Social integration and survival after diagnosis of colorectal cancer. Cancer. (2018) 124:833-40. doi: 10.1002/cncr.31117

45. Engelen VDI. DE GEVOLGEN VAN DE CORONACRISIS VOOR KANKERPATIËNTEN: WAT IS JOUW ERVARING? (2020). Available online at: https://nfk.nl/media/1/Downloads/200429-DJE-corona_eindrapportage_ finale-versie.pdf (accessed June 18, 2020).

46. Delibegovic A, Sinanovic O. The influence of palliative care on the level of anxiety and depression in lung cancer patients. Med Arch. (2013) 67:2635. doi: 10.5455/medarh.2013.67.263-265

47. Kedia SK, Collins A, Dillon PJ, Akkus C, Ward KD, Jackson BM. Psychosocial interventions for informal caregivers of lung cancer patients: a systematic review. Psychooncology. (2020) 29:251-62. doi: 10.1002/pon.5271

48. IASC. IASC Guidelines on Mental Health and Psychosocial Support in Emergency Settings. Geneva: IASC (2007).

49. Ryan H, Schofield P, Cockburn J, Butow P, Tattersall M, Turner J, et al. How to recognize and manage psychological distress in cancer patients. Eur J Cancer Care. (2005) 14:7-15. doi: 10.1111/j.1365-2354.2005. 00482.x

50. Cameron RA, Mazer BL, DeLuca JM, Mohile SG, Epstein RM. In search of compassion: a new taxonomy of compassionate physician behaviours. Health Expect. (2015) 18:1672-85. doi: 10.1111/hex.12160

51. Hillen MA, de Haes HC, van Tienhoven G, van Laarhoven HW, van Weert JC, Vermeulen DM, et al. Oncologists' non-verbal behavior and analog patients' recall of information. Acta Oncol. (2016) 55:6719. doi: 10.3109/0284186X.2015.1120884

52. Lai J, Ma S, Wang Y, Cai Z, Hu J, Wei N, et al. Factors associated with mental health outcomes among health care workers exposed to coronavirus disease 2019. JAMA Netw Open. (2020) 3:e203976. doi: 10.1001/jamanetworkopen.2020.3976

53. Maslach C, Schaufeli WB, Leiter MP. Job burnout. Annu Rev Psychol. (2001) 52:397-422. doi: 10.1146/annurev.psych.52.1.397

54. McClain CS, Rosenfeld B, Breitbart W. Effect of spiritual well-being on end-of-life despair in terminally-ill cancer patients. Lancet. (2003) 361:16037. doi: $10.1016 / \mathrm{S} 0140-6736(03) 13310-7$

55. Zare A, Bahia NJ, Eidy F, Adib N, Sedighe F. The relationship between spiritual well-being, mental health, and quality of life in cancer patients receiving chemotherapy. J Family Med Prim Care. (2019) 8:17015. doi: 10.4103/jfmpc.jfmpc_131_19

Conflict of Interest: The authors declare that the research was conducted in the absence of any commercial or financial relationships that could be construed as a potential conflict of interest.

Copyright $\odot 2020$ Schoenmaekers, Hendriks and van den Beuken-van Everdingen. This is an open-access article distributed under the terms of the Creative Commons Attribution License (CC BY). The use, distribution or reproduction in other forums is permitted, provided the original author (s) and the copyright owner(s) are credited and that the original publication in this journal is cited, in accordance with accepted academic practice. No use, distribution or reproduction is permitted which does not comply with these terms. 